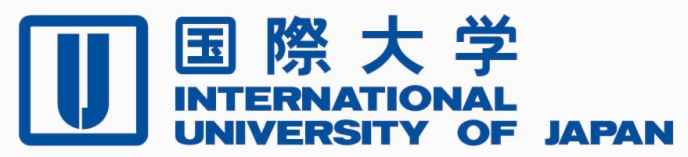

Economics \& Management Series

EMS-2011-01

\title{
Spatial Analysis of the Japanese Gas Industry
}

\author{
Akio Kusakabe \\ Alumunus 2010, International University of Japan
}

Jinhwan Oh

International University of Japan

January 2011

IUJ Research Institute

International University of Japan

These working papers are preliminary research documents published by the IUJ research institute. To facilitate prompt distribution, they have not been formally reviewed and edited. They are circulated in order to stimulate discussion and critical comment and may be revised. The views and interpretations expressed in these papers are those of the author(s). It is expected that the working papers will be published in some other form. 


\title{
Spatial Analysis of the Japanese Gas Industry
}

\begin{abstract}
Akio Kusakabe and Jinhwan $\mathrm{Oh}^{1}$
This study analyzes gas prices, costs, and expenditures in Japan from a spatial perspective. The main findings are as follows: (1) Gas prices, costs, and expenditures exhibit spatially dependent patterns throughout Japan and are related to the service area locations of the gas distributors. (2) Regional conditions, including weather, production shipment, and availability and method of procuring domestic natural gas are the main determinants influencing gas prices and cost levels in Japan. These findings indicate that the Japanese government pays special attention to geographical perspectives in dealing with gas policies.
\end{abstract}

Keywords: ESDA, Moran’s I, Spatial Regression, Gas Industry, Japan

\section{INTRODUCTION}

Since 1995, the Japanese government has partially deregulated ${ }^{2}$ its gas ${ }^{3}$ industry to reduce notoriously high gas prices. This policy has been partially successful in that the average price of gas declined by 5.6\% between 1995 and 2005 despite soaring import prices for Liquefied Natural Gas (LNG) during that period. However, the issue of gas price differentials (the difference between the lowest and highest gas prices) among companies and sectors has not yet been resolved. According to the Cabinet Office of the Japanese Government (2009), Japan had 213 gas distributors as of July 2008, and the company with the highest gas prices was charging approximately 2.5 times more than the one with the lowest price (2.73 and 2.34 times in the private and public sectors). This price gap is remarkable when compared with the prices charged by 10 electricity distributors in Japan with a difference of merely 1.13 times between the highest and the lowest prices. Kainou (2008) indicated that the standard deviations of the average gas prices increased from 0.69 in 1995 to 0.93 in 2005

\footnotetext{
1 Akio Kusakabe: Assistant Manager, Group III, Gas Resources Dept. Toho Gas Co. LTD. kusa@tohogas.co.jp; Jinhwan Oh: Assistant Professor, Graduate School of International Relations, International University of Japan. joh@iuj.ac.jp

${ }^{2}$ The Japanese government has expanded the extent of deregulation through several phases, which currently includes consumers who use over $100,000 \mathrm{~m}^{3}$ of gas per year. These consumers can select any gas distributor within the competitive market.

${ }^{3}$ The term "gas” in this paper refers to "toshi gas,” which literally means "city gas.” A few studies have translated the term as "town gas.” However, in reality, "toshi gas" includes both city and town gas, and this paper simply adopts the term "gas."
} 
(from 0.58 to 0.73 in residential sectors and from 0.99 to 1.03 in the commercial and industrial sectors), suggesting that the gas price gap is on the rise; furthermore, the response to resolve the problem by the Ministry of Economy, Trade and Industry (METI) in forming several subcommittees and working groups ${ }^{4}$ has proved to be quite ineffective.

The primary objectives of this research were to understand the reasons for the continued existence of large price differentials in the Japanese gas industry and to identify the main determinants affecting gas prices, costs, and expenditures. A few studies have attempted to examine how gas prices are determined. For example, using data from eight countries, ${ }^{5}$ Lee et al. (1999) found that demand density such as population density is a statistically significant determinant for improving the management efficiency of a gas distributor.

This study emphasizes the spatial approach so that the regional dependent patterns and determinants of gas prices, costs, and expenditures in Japan can be identified. After examining the spatial dependence patterns of these gas prices, costs, and expenditures, their determinants were then identified. Unlike previous studies examining only gas prices, gas prices as well as their main costs including manufacturing costs and supply-sales-general administration expenses are examined in this paper. Overall, the research attempts to answer the following questions:

1. Do gas prices, manufacturing costs, and supply-sales-general administration expenses in Japan exhibit spatially dependent patterns?

2. Are the spatial dependence patterns in the Japanese gas industry statistically significant?

3. Can regional features such as weather, regional demand density, and size be considered as determinants affecting the aforementioned gas prices, costs, and expenditures?

First, an Exploratory Spatial Data Analysis (ESDA) was conducted to answer the first question. Second,

\footnotetext{
${ }^{4}$ The minutes of these group meetings, which highlight gas price issues, can be accessed from the website of the Agency for Natural Resources and Energy (ANRE). http://www.enecho.meti.go.jp/gasHP/index.html

5 The US, Canada, the UK, Italy, Germany, France, Korea, and Japan.
} 
the significance of spatial dependence was examined by employing the non-geographical conventional model, which uses economies of scale, management efficiency, and the characteristics and purchase methods of major raw materials as independent variables to answer the second question. Finally, the geographically specified model, which uses the aforementioned regional features as independent variables, was employed to answer the third question.

This paper is organized as follows: Chapter 2 provides an overview of the current Japanese gas industry and reviews the major literature on Japanese gas prices. Chapter 3 describes the data used in the paper. Chapter 4 presents the methodology employed in this research. Chapter 5 investigates the spatially dependent patterns of gas prices using the ESDA. Chapter 6 examines the significance of geographical location and important factors affecting the Japanese gas industry using standard linear regression and spatial regression models. Chapter 7 concludes the study.

\section{AN OVERVIEW OF THE JAPANESE GAS INDUSTRY AND RELATED STUDIES}

\subsection{Gas Pricing System in Japan}

Currently, two gas pricing systems are used in Japan, one for the regulated sector and the other for the deregulated sector. The former is calculated using a cost-based pricing procedure, ${ }^{6}$ described in Figure 1, and the latter is determined on the basis of each gas distributor's decisions without any government approval, similar to the market oriented pricing system. Although gas distributors can freely decide gas prices for the deregulated sectors without government approval, they are obligated to provide an exclusive balance sheet of the deregulated as well as regulated sectors to METI, the regulation authority.

As a result, the process of cost calculation for the deregulated sectors is similar to that of the regulated sectors. The deregulated sectors also follow a cost-based principle in order to prevent

\footnotetext{
${ }^{6}$ Ordinal No. 16 (2004) of METI compelled the gas distributors in Japan to follow the detailed rules of cost-based gas pricing for both regulated and deregulated sectors.
} 
unreasonable pricing behavior such as dumping for overcoming competition within the sector. In fact, METI rigorously monitors whether or not gas prices in the deregulated sectors are set at an unreasonably low level, as this pricing may create an additional burden on consumers in the regulated sectors. Figure 1 indicates that this cost-based pricing is designed for equalizing total cost, profit, and taxes $^{7}$ with total revenue, where the profit is regulated by the government.

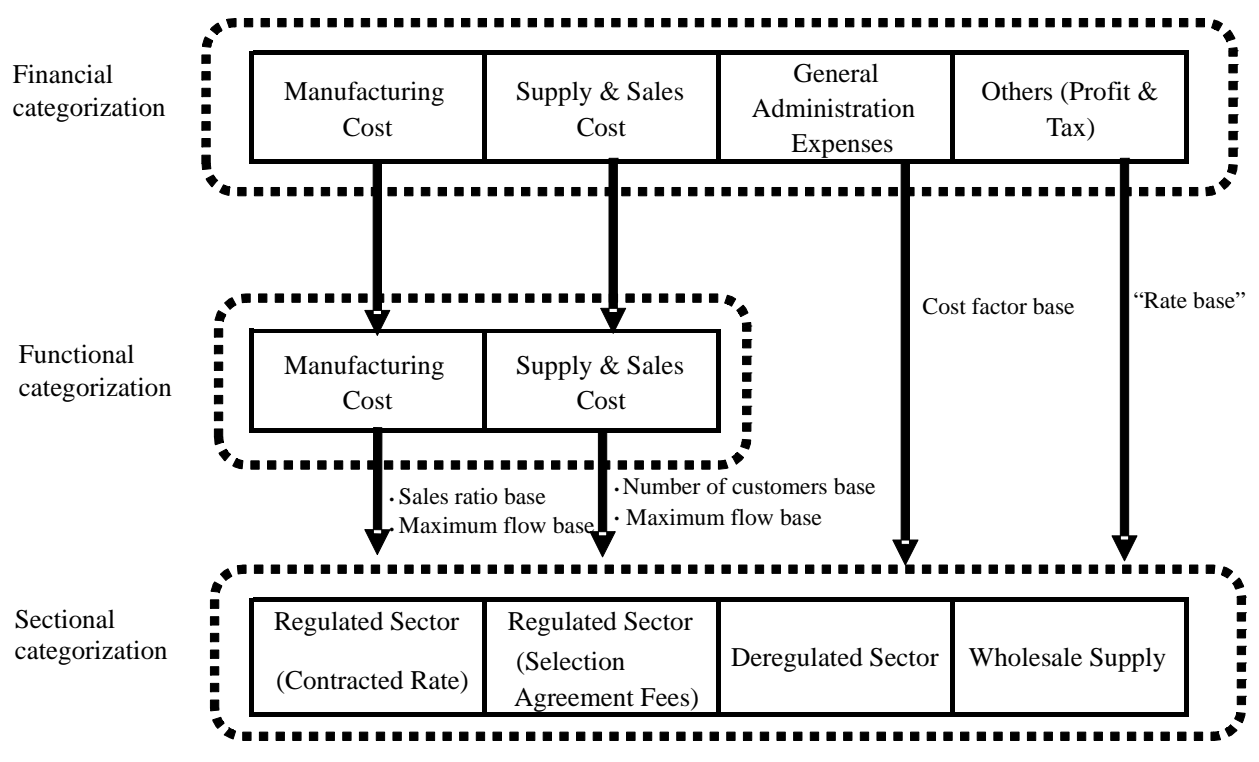

Based on Ordinal No. 16 (February 24, 2004) of the Ministry of Economy, Trade and Industry

Figure 1. Summary of the cost-based pricing system

According to the Consumer Affairs Agency (2010), this pricing system is intended to (1) clarify grounds for gas pricing, (2) prevent excessive profits or losses for gas distributors, (3) protect consumers from the unreasonable burden of excessive gas prices, and (4) encourage gas distributors to improve their safety level by investing in equipment for the long term. However, in reality, because the cost calculation is based on projections for the following year, a deficit in the balance of payments during the actual settlement of accounts is possible in the case of unexpected external shocks such as escalating imported gas prices. Moreover, this cost-based pricing procedure negatively impacts cost reduction in the regulated sectors. Although the deregulated sectors have an incentive to decrease the

\footnotetext{
${ }^{7}$ The gas distributors that are managed by the public sector are exempted from taxation.
} 
cost of gas due to pressure from competitors, the regulated sector may discourage gas distributors from reducing their gas costs because the distributors are monopolists in their regional markets. In order to prevent such a problem, the METI implemented a yardstick regulation in 1995 for the pricing system

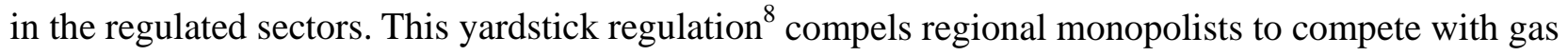
distributors. In particular, the regulatory authority divides all the gas distributors into several categories on the basis of four attributes: number of customers, region, gas source (LPG or LNG), and type of management (public or private). On the basis of this classification, the regulatory authority examines the cost performance of the gas distributors. Consequently, although gas distributors may not compete directly with each other, they must compete indirectly in terms of cost.

\subsection{Studies on Gas Pricing in Japan}

Unlike the present study's objective of emphasizing geographical features for analyzing the Japanese gas industry, the majority of existing studies focused on analyzing the cost structures and cost-based pricing systems of gas distributors. A study by Takenaka and Urano (1994) analyzed the effects of economy of scale on gas costs by employing the transcendental logarithmic cost function on the manufacturing, supply, sales, and total cost of gas. A study that used financial data from Tokyo Gas Co., Ltd. from 1955 to 1991 examined the existence of economies of scale. This study indicated that despite the disturbance caused by two major oil crises during the period, economies of scale were observed in the Tokyo Gas case; such economies of scale exceedingly depended on regional demand structure such as industrial concentration. A study by Ito (2009) investigated the significant factors of the gas price differential among Japanese gas distributors on the basis of the Cobb-Douglas cost function. Although Takenaka and Urano (1994) focused on economies of scale, this study comprehensively analyzed the cost structure by employing the cross-sectional datasets from 2004. The present study revealed that economies of scale (sales volume), efficiency of the gas pipeline network

\footnotetext{
${ }^{8}$ Ordinal No. 5 (January 18, 2001) of the ANRE defines evaluation methods in the yardstick regulation.
} 
(the total sales divided by total length of pipeline), and demand structure (the ratio of sales of the industrial sectors) are significant. Moreover, Yokokura (1994) suggested that both economies of scale (sales volume) and demand structure (the amount of gas use per customer) are scarcely controlled by gas distributors.

In another direction, the study by Kainou (2007) claimed that the differential of management efficiency is a rather significant factor of gas price differential. Using 1995 and 2005 panel data, this study analyzed the factors of cost differential by focusing on the differences in management efficiency including the amount of gas utilized per customer, diffusion rate of the gas utilized in the service area, and annual load rate. Another relevant study was conducted by METI (2006), ${ }^{9}$ which also indicated that the management efficiency of gas distributors significantly reduces gas prices. The study identified the four factors that influence the gas price differential by employing 2004 cross-sectional data: the sales volume per book value of supply equipment, sales volume per $10 \mathrm{~m}$ conduit, purchase of natural gas through a pipeline, and private sector management. These two studies claimed that deregulation policies are effective for domestic gas price differential because these policies may increase the management efficiency of gas distributors.

\section{DATA SOURCES AND DESCRIPTION}

\subsection{Data Sources and Software}

First, data on $184^{10}$ gas distributors were obtained from the Gas Annual Report compiled by the Agency for Natural Resources and Energy (ANRE) (2007). The data include the annual gas supply (unit: megajoule), diffusion rate of gas in the service area (unit: \%), annual depreciation expenditure (unit: yen), annual manufacturing cost (unit: yen), annual supply and total sales cost (unit: yen), and

\footnotetext{
${ }^{9}$ The $6^{\text {th }}$ meeting of the competition environment planning committee on July 27, 2006 indicated the result of the regression analysis of gas prices in Japan.

${ }^{10}$ The reason for the reduction in the number of distributors from 211 to 184 is provided in Section 3.3.
} 
annual total general expenditure (unit: yen). Additionally, this research employs 1) the Gas Business Handbook published by ANRE (2007), and 2) a survey ${ }^{11}$ of the Japanese gas wholesale market conducted by METI in order to obtain information on the characteristics and purchase methods (pipeline, LNG terminal, or satellite system) of the main raw materials (LPG, LNG, or Domestic Natural Gas) for gas in Japan.

Second, in addition to the abovementioned internal data from gas distributors, this research measured external data, most of which are regionally or geographically specific. These data were collected from various sources. First, the data for 2007 on population, number of households, inhabitable land area (unit: $\mathrm{km}^{2}$ ) for each gas distributor's service area, and weather conditionsincluding the average temperature, highest temperature, lowest temperature, and number of days in a year that are covered by snow-were obtained from the Statistical Observations of Municipalities and Prefectures published by the Ministry of Internal Affairs and Communications (2009). Second, data on production shipment (unit: yen) for each gas distributor's service area were obtained on the basis of Indices of Industrial Production conducted by METI (2007). Finally, the National City Field Data (with shapefile) were collected from ESRI Japan Co., Ltd. and the Gas Annual Report (FY 2007) in order to create maps indicating gas price distribution. These data were analyzed using two different kinds of software: GeoDa 0.9.5-I (Beta), for examining the spatial autocorrelation using Moran’s I and conducting spatial regression analyses, and MANDARA 9.13, for editing maps.

\subsection{Regression Models}

In contrast, the geographically specified model modifies the conventional model by including two geographical variables - (1) weather, measured by SNOW DAYS, and (2) regional demand, measured by $L O G P R D$ and $L O G P R$ — for the purpose of highlighting geographical factors affecting gas prices. Tables 1 and 2 present the definition of the variables and way in which these variables were

\footnotetext{
${ }^{11}$ The survey was introduced in the $4^{\text {th }}$ meeting of the competition environment planning committee on June $19,2006$.
} 
employed in each model (see Appendix A for detailed explanations of each variable).

\section{Table 1. Definition Table of Variables}

\begin{tabular}{|c|c|}
\hline Variable name & Definition \\
\hline \multicolumn{2}{|l|}{ Dependent variable } \\
\hline PRICE & Town gas price per one unit of gas $(46 \mathrm{MJ}) *$ \\
\hline MCOST & Manufacturing cost per one unit of gas (46 MJ)* \\
\hline SSGEX & Supply cost \& sales cost and general administration expenses per one unit of gas (46 MJ)* \\
\hline \multicolumn{2}{|l|}{ Independent variable } \\
\hline LOG SUPPLY & Log of quantity of gas supplied annually \\
\hline DEP & Depreciation expense per unit of gas $(46 \mathrm{MJ}) *$ \\
\hline DIFFUSION R & Diffusion rate of town gas within the service area of a gas distributor \\
\hline SNOW DAYS & The number of snow covered days in a year \\
\hline$L O G P R$ & Log of production shipment within the service area of a gas distributor \\
\hline$L O G P R D$ & Log of production shipment density (per $1 \mathrm{~km}^{2}$ ) within the service area of a gas distributor \\
\hline LNGPIPE & 1 if LNG is purchased through a pipeline, and 0 otherwise \\
\hline LNGSATELLITE & 1 if LNG is purchased through a satellite system, and 0 otherwise \\
\hline DNGPIPE & 1 if domestic natural gas is purchased through a pipeline, and 0 otherwise \\
\hline DNGSATTELITE & 1 if domestic natural gas is purchased through a satellite system, and 0 otherwise \\
\hline LPGSATTELITE & 1 if LPG is purchased through a satellite system, and 0 otherwise \\
\hline
\end{tabular}

Table 2. Use of Variables in Each Model

\begin{tabular}{|c|c|c|c|c|c|}
\hline \multicolumn{3}{|c|}{ CONVENTIONAL } & \multicolumn{3}{|c|}{ GEOGRAPHICALLY SPECIFIED } \\
\hline Model 1 & Model 2 & Model 3 & Model 4 & Model 5 & Model 6 \\
\hline $\begin{array}{l}\text { Dependent Var } \\
\text { PRICE }\end{array}$ & $\begin{array}{l}\text { Dependent Var } \\
\text { MCOST }\end{array}$ & $\begin{array}{l}\text { Dependent Var } \\
S S G E X\end{array}$ & $\begin{array}{l}\text { Dependent Var } \\
\text { PRICE }\end{array}$ & $\begin{array}{l}\text { Dependent Var } \\
\text { MCOST }\end{array}$ & $\begin{array}{l}\text { Dependent Var } \\
S S G E X\end{array}$ \\
\hline Independent Var & Independent Var & Independent Var & Independent Var & Independent Var & Independent Var \\
\hline LOG SUPPLY & LOG SUPPLY & LOG SUPPLY & SNOW DAYS & SNOW DAYS & SNOW DAYS \\
\hline$D E P$ & $D E P$ & $D E P$ & $L O G P R D$ & LOG PR & $L O G P R D$ \\
\hline DIFFUSION $R$ & LNGPIPE & DIFFUSION R & LNGPIPE & LNGPIPE & LNGPIPE \\
\hline LNGPIPE & LNGSATELLITE & LNGPIPE & LNGSATELLITE & LNGSATELLITE & LNGSATELLITE \\
\hline LNGSATELLITE & DNGPIPE & LNGSATELLITE & DNGPIPE & DNGPIPE & DNGPIPE \\
\hline DNGPIPE & DNGSATTELITE & DNGPIPE & DNGSATTELITE & LPGSATTELITE & LPGSATTELITE \\
\hline DNGSATTELITE & LPGSATTELITE & DNGSATTELITE & LPGSATTELITE & $D E P$ & $D E P$ \\
\hline LPGSATTELITE & & LPGSATTELITE & $D E P$ & & \\
\hline
\end{tabular}

Note: DIFFUSION R was omitted in Model 2 because it is irrelevant to manufacturing cost. It has only to do with downstream expenses such as supply cost and sales cost. See Appendix A for further explanation on each variable.

In contrast, the geographically specified model modifies the conventional model by including two geographical variables-(1) weather, which is measured by SNOW DAYS, and (2) regional demand, which is measured by $L O G P R D$ and $L O G P R$-for the purpose of highlighting geographical factors affecting gas prices. Tables 1 and 2 present the definition of the variables and manner in which these variables were employed in each model (see Appendix A for detailed explanations for each variable).

\subsection{Number of Observations}

In order to perform a spatial analysis, the municipalities from the map in which there are no 
gas service areas were excluded. The units of observation in this paper were the gas distributors; these distributors have monopoly powers in each area. However, the service areas of 27 gas distributors overlap within the same municipality; therefore, they were omitted in the process of editing the map. In addition to the 27 abovementioned gas distributors, two other gas distributors were excluded—Nankai and Okinawa Gas_-for they are located on an isolated island, and their gas service area is rather distant from the service area of a neighboring gas distributor. Consequently, a total of 29 distributors was excluded, and the number of observations in this paper was reduced to 184 (from a total of 213 distributors in 2007), shown in Figure 2.

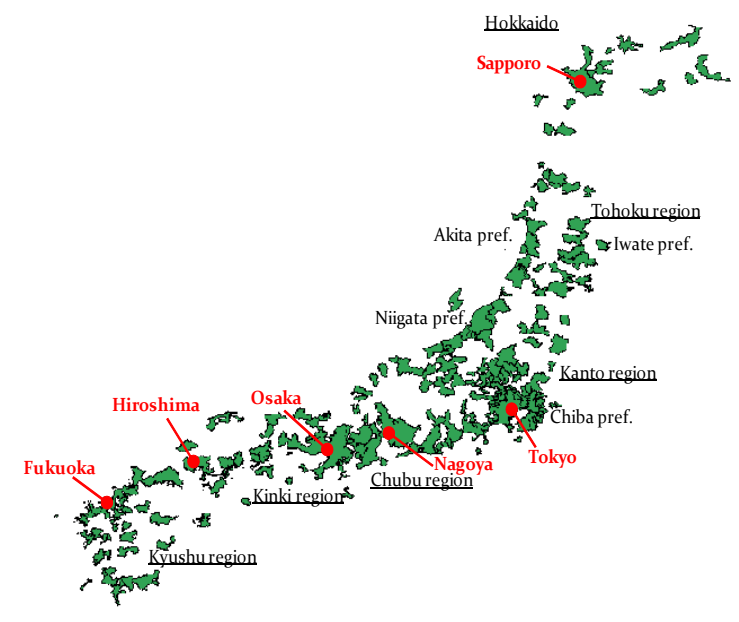

Figure 2. Municipality map used for this study

\section{METHODOLOGY}

\subsection{Exploratory Spatial Data Analysis (ESDA)}

In order to answer the first question, an ESDA was conducted. According to Anselin et al. (2007), an important aspect of the ESDA is visualization through the use of a map of extreme values. The key concept in this analysis is spatial autocorrelation, which implies that neighboring areas have more similarities than distant areas. Similarity in this paper implies similar gas price (or cost) levels among neighboring areas. 
Both global and local spatial autocorrelation of gas prices in Japan are examined in the paper. First, in order to measure the degree of global spatial autocorrelation, Moran's I is used extensively. This index indicates whether or not a specific variable exhibits spatial data patterns statistically in the overall map. The index ranges from -1 to 1 , where 1 and -1 indicate a strong positive and negative spatial autocorrelation and 0 indicates a random walk. The definition of Moran’s I for a specific variable $Z_{i}$ at location $i$ is presented below.

$$
l=\frac{\sum_{t j} W_{t j}\left(Z_{t}-\bar{z}\right)\left(Z_{\bar{p}}-\bar{Z}\right)}{n} / \sigma^{2}(Z)
$$

where $\sigma^{2}$ is the sample variance and $w_{t, j}$ is the proximity-weighted matrix. ${ }^{12}$

Although Moran's I is useful in capturing the global spatial autocorrelation, it is based on the assumption that every area is homogeneous in terms of spatial autocorrelation. Therefore, in order to clarify the differences among each of the areas in terms of spatial autocorrelation at a local level, an index known as Local Indicators of Spatial Association (LISA) may be employed. The indicator for each location is presented as:

$$
I_{t}=\frac{\sum_{i} W_{t j}\left(Z_{t}-\bar{Z}\right)\left(Z_{i}-Z\right)}{\sum_{t}\left(Z_{t}-\bar{Z}\right)^{2}}
$$

According to Anselin (1995), the indicator identifies areas that exhibit both extreme and geographically homogeneous values. For each location, the indicator suggests five patterns:

Locations with high values and similar neighbors: high-high, also known as hot spots. (Spatial autocorrelation is positive.)

$>$ Locations with low values and similar neighbors: low-low, or cold spots. (Spatial autocorrelation is positive.)

Locations with high values and low-value neighbors: high-low. These locations are also

\footnotetext{
${ }^{12}$ This spatially contiguous matrix guarantees that every observation has an equal number of neighbors. In other words, this matrix is known as the k-nearest neighbor weight matrix. The most widely used number of $k$ is 4 (GeoDa default), so the convention is followed here.
} 
known as potential spatial outliers. (Spatial autocorrelation is negative.)

Locations with low values and high-value neighbors: low-high, also known as potential spatial outliers. (Spatial autocorrelation is negative.)

Locations with no significant local autocorrelation.

\subsection{Regression Analyses (Test of Spatial Dependence)}

In order to examine the significance of spatial dependence and identify determinants of gas prices (and costs) in Japan, this study employed two regression methods: standard ordinary least square (OLS) regression and the spatial regression model. First, the standard OLS model is represented by the following equation:

$$
y_{i}=\sum_{i} \alpha_{i} x_{i j}+\varepsilon_{i}
$$

where $i$ refers to the $\mathrm{i}^{\text {th }}$ gas distributor.

Second, the two models of spatial regression are the spatial lag and spatial error model. First, the spatial lag model is formulated by inserting the spatially lagged dependent variable (Wy) into the right hand side of the standard linear regression model. This model is defined as:

$$
y=\rho W y+X \alpha+\varepsilon,
$$

where $\mathrm{y}$ is a vector ( $\mathrm{i} \times 1$ ) of observations for the dependent variable, $\mathrm{X}$ is a matrix ( $\mathrm{i} \times \mathrm{n}$ ) of 2 independent variables of the coefficient, $\alpha$ is a vector $(\mathrm{n} \times 1), \varepsilon$ is a vector $(\mathrm{n} \times 1$ ) of error terms, Wy is a spatial autoregressive matrix ( $\mathrm{i} \times 1$ ), and $\rho$ is the spatial autoregressive parameter. Second, the spatial error model incorporates a spatial autoregressive process in the error terms of the standard linear regression model. This spatial error model is based on the assumption that the error terms of neighboring observations are correlated, and the model is defined in the following model:

$$
y=\mathrm{X} \alpha+\varepsilon\left(\varepsilon=\lambda W s+u, u \sim N\left(0, \sigma^{2} D\right)\right.
$$

where a vector of $\lambda$ is the spatial autoregressive coefficient for $\mathrm{Wa}$, $\mathrm{u}$ is an error term, $\sigma^{2}$ is a variance, and $I$ is a unit matrix. 
This paper employs the test of a spatial dependence framework, suggested by Anselin (2005), in order to identify which regression method—OLS, spatial lag, or spatial error—must be employed (a flowchart describing this test is provided in Appendix C).

\section{RESULTS: DESCRIPTION OF SPATIAL DEPENDENCE}

\subsection{Exploratory Spatial Data Analysis (ESDA)}

In order to answer the first question (whether or not spatial dependence exists in the Japanese gas industry), the presence of a spatially dependent pattern throughout Japan in terms of the three dependent variables was investigated, which is shown graphically in three maps (Figure 3). The areas below one, two, and three standard deviations from the mean are indicated in blue, whereas the areas above one, two, and three standard deviations from the mean are indicated in red. ${ }^{13}$
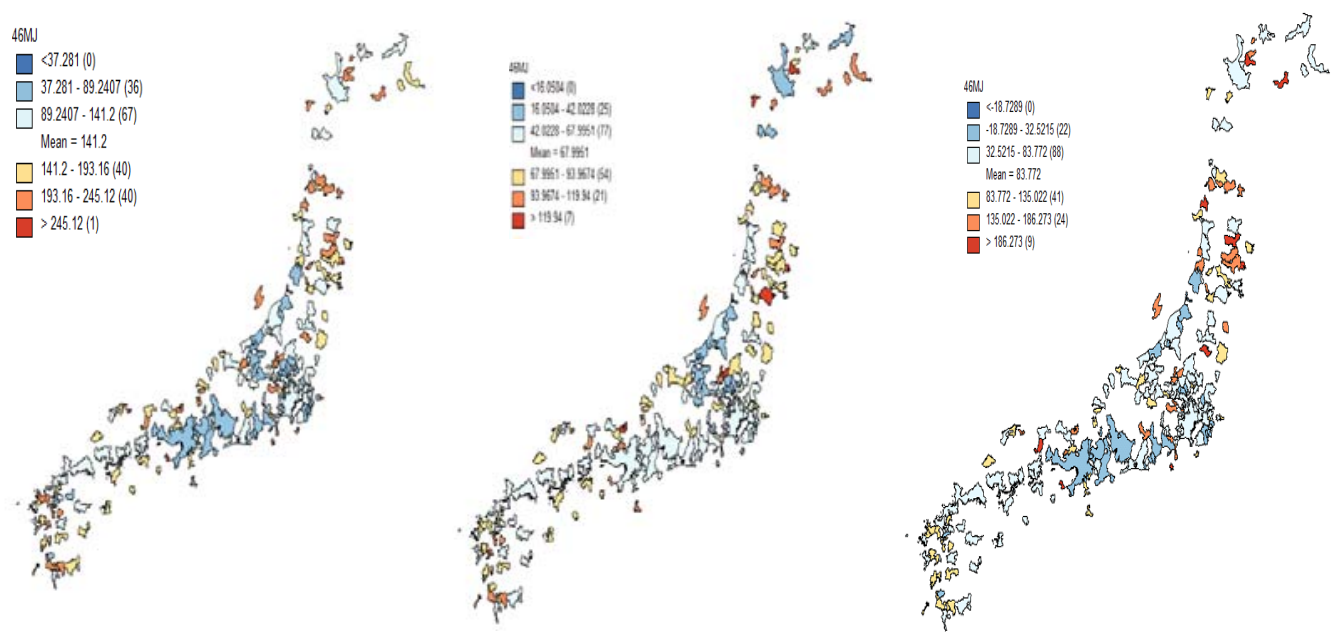

\section{Figure 3: Maps describing each variable (PRICE, COST, and SSGEX [from the left])}

The three findings based on Figure 3 are indicated as follows. First, all three dependent variables exhibit a similar spatially dependent pattern; gas prices, costs and expenditures in a particular area appear to influence the areas. Areas with lower gas prices, costs, and expenditures are concentrated in the Pacific belt zone where major cities like Tokyo, Osaka, Nagoya, and Fukuoka are

\footnotetext{
13 Maps in color can be provided upon request.
} 
located, possibly implying that industrial development is correlated with gas price levels in Japan. Second, Niigata and Akita prefectures also indicate relatively low gas prices despite low levels of urbanization because these prefectures possess domestic gas fields with easy access. Finally, the Tohoku and Southern part of the Kyusyu region exhibit relatively high gas prices because they have not yet switched to Natural Gas from LPG, indicating that differences in raw materials may be a significant determinant of gas price.

\subsection{Global Spatial Autocorrelation}

Figure 4 indicates the univariate Moran's I scatterplots for global spatial autocorrelation of the three dependent variables. A casual examination indicates that all three dependent variables—PRICE, MCOST, and SSGEX — appear to exhibit spatially dependent patterns. A thorough examination follows for determining whether or not this dependence is statistically significant.

Moran's I Table

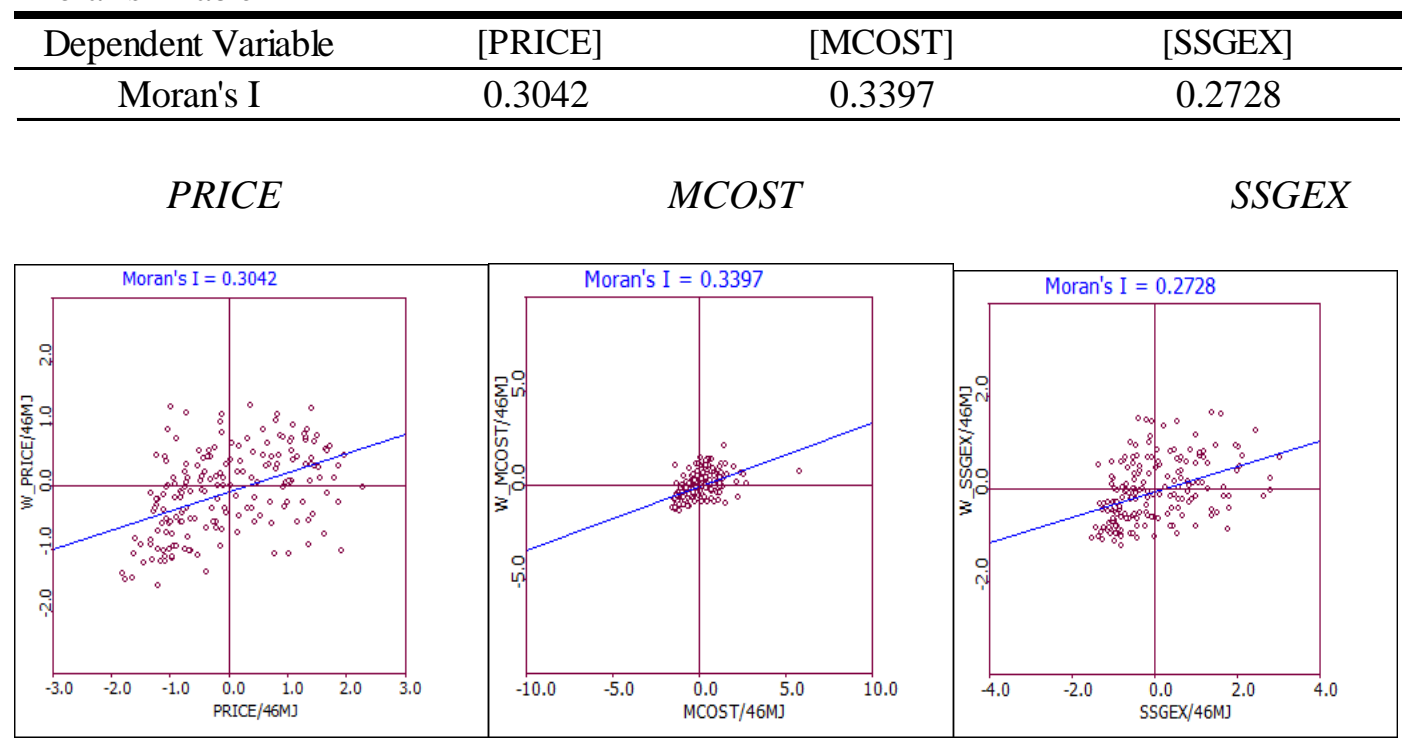

Figure 4. Moran's I scatterplot diagram of the three dependent variables

The vertical axis represents the spatially lagged variable, which denotes the neighboring gas distributors' gas prices and costs. On the other hand, the horizontal axis represents the gas distributor's observed gas price and costs. Moran's I for the three dependent variables, the slopes of these graphs, is approximately 0.3 , which indicates an overall positive spatial autocorrelation throughout Japan. 
Subsequently, in order to assess the significance of Moran’s I against the null hypothesis, which states that there is no spatial autocorrelation in gas prices or their costs, a permutation procedure was conducted using GeoDa. This procedure indicates that the three dependent variables have rather low p-values (0.010), confirming the statistical significance of global spatial dependence.

\subsection{Local Indicators of Spatial Association (LISA)}

Subsequently, the LISA cluster maps of the three dependent variables are indicated below. Although Moran’s I determines the degree of spatial autocorrelation at the global level across Japan in the previous section, it does not identify the areas that indicate a statistically strong spatial dependence on the local level. This section employs LISA in order to investigate this issue.LISA cluster maps for the three dependent variables are presented in Figure 5.

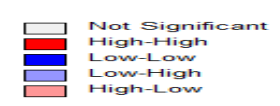
PRICE
MCOST
SSGEX

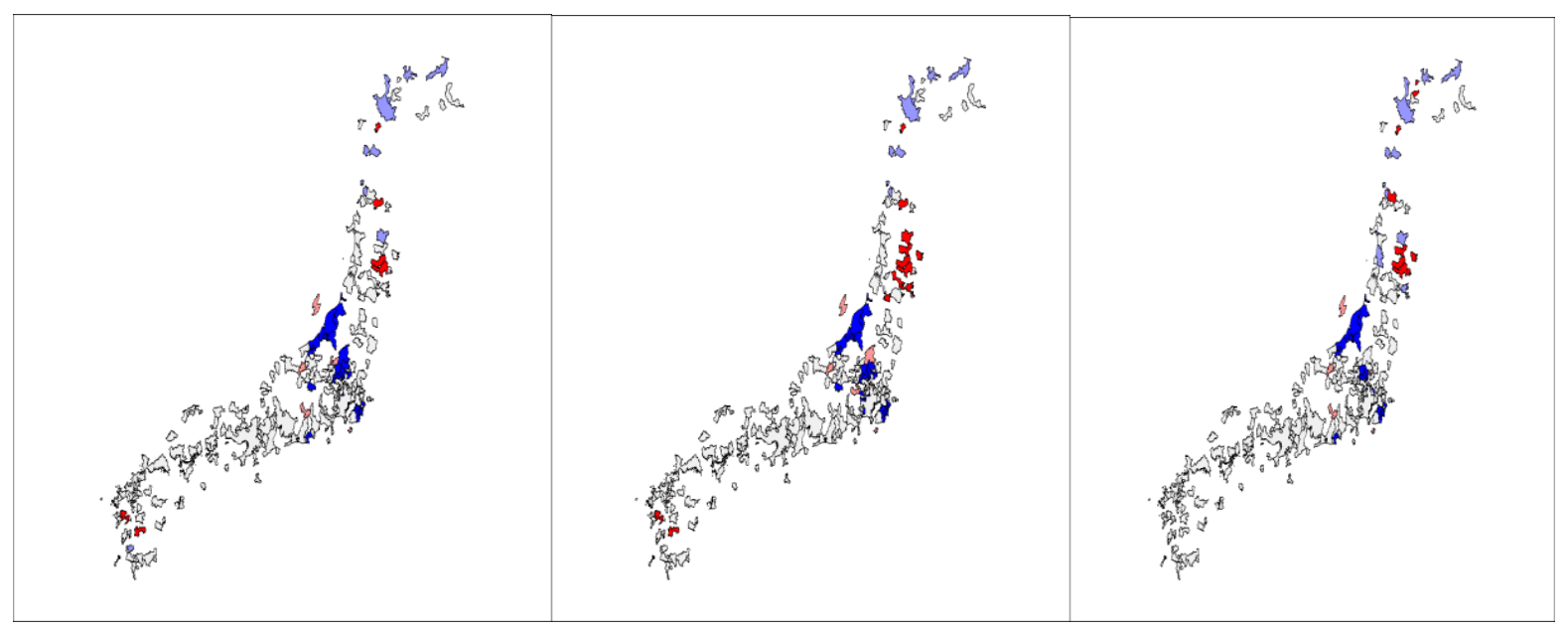

\section{Figure 5. LISA Cluster Map for the three dependent variables}

The three maps reveal the following findings. First, the Tokyo-based Kanto region and Niigata, Gunma, and Chiba prefectures indicate a low-low pattern. These areas are located along the interdomestic gas pipeline network, ${ }^{14}$ managed by the Inpex corporation (see Appendix B). This result may

\footnotetext{
${ }^{14}$ Produced natural gas in the Niigata gas field is transported through this $1,300 \mathrm{~km}$ trunk pipeline network that stretches across the Kanto-Koshinetsu region surrounding the Tokyo metropolitan area.
} 
indicate the significant impact of a domestic gas pipeline network on reducing gas prices and associated costs. Second, the high-high clusters can be observed in the Iwate prefecture and certain parts of Hokkaido, both of which use LPG as their primary source of energy, for they cannot access either domestic gas fields or LNG terminals. Third, certain other parts of Hokkaido indicate a low-high pattern. This area is controlled by Hokkaido Gas Co., Ltd., the ninth largest gas distributor (based on sales volume) in Japan, a company that uses LNG as the main input source by purchasing LNG from Tokyo Gas Co., Ltd. Finally, a few small clusters are observed in the Tohoku region, including Akita, Miyagi, and Fukushima prefectures, whose primary access is either a domestic gas field or an LNG terminal (Akita and Fukushima prefectures have domestic gas fields and Miyagi prefecture has an LNG terminal).

In summary, the ESDA result indicates that the Japanese gas industry exhibits spatially dependent patterns. Moreover, industrial and domestic gas areas appear to be associated with areas where gas prices (costs) are low. In particular, the inter-domestic gas pipeline network appears to be a key element for lowering gas prices, costs, and expenditures. On the other hand, LPG areas tend to exhibit high prices and costs. Additionally, considering the fact that the high-high clusters are concentrated in Iwate and Hokkaido, cold weather may be one of the factors responsible for increasing gas prices and costs in Japan.

\section{RESULTS: REGRESSION ANALYSES}

Chapter 5 indicated that all the three dependent variables_-PRICE, MCOST, and SSGEXdisplay spatially dependent patterns with statistical significance. As follow-up research, this chapter examines several factors that may operate as determinants of those dependent variables. This chapter begins with the conventional model, whose variables were indicated in some previous studies. Subsequently, the geographically specified model is introduced in order to investigate whether or not 
regional factors affect gas prices or costs in Japan.

\subsection{Conventional Model}

The regression results and evaluation of spatial dependence for the three conventional models using the OLS method are presented in Table 3. All three conventional models indicate that LOG SUPPLY, which represents the annual gas supply volume and measures economies of scale, bears a negative relationship with each statistically significant dependent variable. $D E P$, which represents the depreciation expenses and measures management efficiency, also indicates a statistically significant relationship with the three dependent variables in a different direction (positive coefficient). On the other hand, DIFFUSION R is insignificant for PRICE and SSGEX at the 5\% significance level. Moreover, the sign of its coefficient is different from the one that is expected. ${ }^{15}$ In this light, DIFFUSION $R$ is no longer a proxy of management efficiency. Therefore, in the geographically specified model, DIFFUSION R is not used. Subsequently, the coefficients of DNGPIPE are found to be negative. This result implies that the domestic gas pipeline strongly contributes to decreasing gas prices, manufacturing costs, and expenditures. LPGSATELLITE, on the other hand, indicates positive coefficients.

\footnotetext{
${ }^{15}$ This difference is the result of the government ensuring that the base charge for such customers remains low. In fact, the base charge is even lower than the actual cost such as the gas meter reading cost. This unreasonable base charge pricing originates from the point of view that small gas users are inadequately protected. The higher diffusion rate may be associated with the higher proportion of small gas users, which may consequently result in an increase in the price and cost of one unit of gas.
} 
Table 3. Regression results for the conventional models (OLS)

\begin{tabular}{|c|c|c|c|c|c|c|}
\hline & \multicolumn{2}{|c|}{ Model 1} & \multicolumn{2}{|c|}{ Model 2} & \multicolumn{2}{|c|}{ Model 3} \\
\hline "Regression Method & \multicolumn{2}{|c|}{ OLS } & \multicolumn{2}{|c|}{ OLS } & \multicolumn{2}{|c|}{ OLS } \\
\hline Dependent Variable & \multicolumn{2}{|c|}{ PRICE } & \multicolumn{2}{|c|}{ MCOST } & \multicolumn{2}{|c|}{ SSGEX } \\
\hline Constant & $203.5179 * * *$ & $(19.22671)$ & $81.84071^{* * *}$ & $(12.26804)$ & $138.2312^{* * *}$ & $(21.19864)$ \\
\hline \multicolumn{7}{|l|}{ Economies of Scale } \\
\hline LOG SUPPLY & $-19.96708 * * *$ & $(2.846263)$ & $-4.655118 * *$ & $(1.800229)$ & $-18.28031^{* * *}$ & $(3.138181)$ \\
\hline \multicolumn{7}{|l|}{ Management Efficiency } \\
\hline$D E P$ & $1.39361^{* * *}$ & $(0.1408288)$ & $0.4731938 * * *$ & $(0.0909476)$ & $1.640715^{* * *}$ & $(0.1552725)$ \\
\hline DIFFUSION R & $0.2026862 *$ & $(0.1058798)$ & & & 0.06250996 & $(0.116739)$ \\
\hline \multicolumn{7}{|c|}{ Characteristics and purchase methods of raw materials } \\
\hline LNGPIPE & 0.7861288 & (5.477563) & 2.874467 & (3.474229) & 0.1604338 & $(6.039352)$ \\
\hline LNGSATELLITE & $14.74988 * *$ & $(6.043592)$ & 4.147252 & (3.910917) & 7.937757 & (6.663433) \\
\hline DNGPIPE & $-28.12594^{* * *}$ & $(5.865017)$ & $-18.01365^{* * *}$ & $(3.66564)$ & $-12.56208^{*}$ & $(6.466543)$ \\
\hline DNGSATELLITE & 6.443652 & $(8.751126)$ & 2.455337 & $(5.666579)$ & 6.298341 & (9.648657) \\
\hline LPGSATELLITE & $34.87293^{* * *}$ & $(6.845745)$ & $21.56271 * * *$ & $(4.420526)$ & $29.04067 * * *$ & $(7.547857)$ \\
\hline R-Squared & \multicolumn{2}{|c|}{0.781270} & \multicolumn{2}{|c|}{0.630727} & \multicolumn{2}{|c|}{0.726692} \\
\hline Log likelihood & \multicolumn{2}{|c|}{847.637} & \multicolumn{2}{|c|}{768.225} & \multicolumn{2}{|c|}{865.602} \\
\hline F-statistic & \multicolumn{2}{|c|}{78.134} & \multicolumn{2}{|c|}{42.9445} & \multicolumn{2}{|c|}{58.1628} \\
\hline \multicolumn{7}{|l|}{ Diagnostics for spatial dependence } \\
\hline Moran's I (residuals) & \multicolumn{2}{|c|}{$0.072563 * *$} & \multicolumn{2}{|c|}{$0.085170^{* *}$} & \multicolumn{2}{|c|}{$0.152602 * * *$} \\
\hline Lagrange Multiplier (lag) & \multicolumn{2}{|c|}{2.4492430} & \multicolumn{2}{|c|}{$4.1211746 * *$} & \multicolumn{2}{|c|}{$2.8989795 *$} \\
\hline Robust LM (lag) & \multicolumn{2}{|c|}{0.9067572} & \multicolumn{2}{|c|}{1.5653799} & \multicolumn{2}{|c|}{0.0225576} \\
\hline Lagrange Multiplier (error) & \multicolumn{2}{|c|}{1.9376676} & \multicolumn{2}{|c|}{2.6694543} & \multicolumn{2}{|c|}{$8.5697382 * * *$} \\
\hline Robust LM (error) & 0.395 & 51818 & 0.1136 & 6597 & 5.69331 & $163 * *$ \\
\hline
\end{tabular}

Note: The significance levels of $1 \%, 5 \%$, and $10 \%$ are denoted by $* * *, * *$, and $*$, respectively.

Standard error s are in parentheses.

Note: "Spatial error and spatial lag are the two types of spatial dependence. The former focuses on the correlations among error terms across different unit, while the latter focuses on the correlations between the two dependent variables. GeoDa provides various diagnostics to test spatial dependence on top of the Moran's I. The statistics are the simple Lagrange Multiplier (LM) test for a missing spatially lagged dependent variable (Lagrange Multiplier (lag)), the simple LM test for error dependence (Lagrange Multiplier (error)), variants of these robust to the presence of the other (Robust LM(lag)), Robust LM (error) for test of error dependence in the possible presence of missing lagged dependent variable, and Robust LM (lag) for the other way around ." (Spatial Regression with GeoDa)

Next, spatial dependences of each model are assessed based on Anselin’s (2005) test of spatial dependence. First, Moran’s I confirms that all three models indicate strong spatial dependence at the 5\% level. In particular, Model 3 indicates a relatively higher Moran’s I, which implies that the current independent variables do not effectively capture the spatial pattern and indicate the existence of hidden factors that influence spatial dependence. Verifying whether or not these geographically specified variables may be one of the hidden factors is an important reason for pursuing another series of regressions using the geographically specified model in this study. In fact, as indicated in the subsequent section, the levels of Moran’s I decrease and values become insignificant when geographically specified variables are considered. Second, three models indicate different results in the 
Lagrange Multiplier (LM) test of the spatial regression model. For Model 1, the results of the LM test indicate that neither the spatial lag nor spatial error model is significant. Therefore, based on Anselin’ (2005) flowchart (Appendix C), the OLS method is more appropriate than the two spatial regression models. In contrast, the LM tests for Model 2 and 3 describe the significance of the spatial regression model. Again, according to Anselin (2005), the spatial lag and spatial error models are appropriate for Models 2 and 3. Therefore, spatial regression analyses were conducted for these models.

Table 4. Regression Results for Conventional Models

\begin{tabular}{|c|c|c|c|c|}
\hline & \multicolumn{2}{|c|}{ Model 2} & \multicolumn{2}{|c|}{ Model 3} \\
\hline Regression Methods & \multicolumn{2}{|c|}{ Spatial lag } & \multicolumn{2}{|c|}{ Spatial error } \\
\hline Dependent Variable & \multicolumn{2}{|c|}{ MCOST } & \multicolumn{2}{|c|}{ SSGEX } \\
\hline$W_{-} M \operatorname{COST} \quad \mathrm{a}$ & $0.135083^{* *}$ & $(0.06667604)$ & & \\
\hline Constant & $75.05201^{* * *}$ & $(12.1721)$ & $142.8794^{* * *}$ & $(20.22275)$ \\
\hline \multicolumn{5}{|l|}{ Economies of Scale } \\
\hline$L O G S U P P L Y$ & $-4.829051^{* * *}$ & $(1.747336)$ & $-18.65246^{* * *}$ & $(2.997321)$ \\
\hline \multicolumn{5}{|l|}{ Management Efficiency } \\
\hline$D E P$ & $0.4414227 * * *$ & $(0.08912683)$ & $1.627791^{* * *}$ & $(0.1493515)$ \\
\hline DIFFUSION R & & & 0.04881728 & $(0.1160448)$ \\
\hline \multicolumn{5}{|c|}{ Characteristics and purchase methods of raw materials } \\
\hline LNGPIPE & -2.743421 & $(3.355471)$ & 0.1026495 & $(5.753463)$ \\
\hline LNGSATELLITE & 3.251175 & $(3.800836)$ & 5.606359 & $(6.28487)$ \\
\hline DNGPIPE & $-16.45397^{* * *}$ & $(3.636495)$ & $-13.36107 * *$ & $(6.387631)$ \\
\hline DNGSATELLITE & 0.831825 & (5.488918) & 3.381302 & (9.705397) \\
\hline LPGSATELLITE & $19.98586 * * *$ & $(4.349456)$ & $27.16346^{* * *}$ & (7.400908) \\
\hline LAMBDA $^{\text {b }}$ & & & 0.2195971 & $(0.09165754)$ \\
\hline R-Squared & \multicolumn{2}{|c|}{0.640764} & \multicolumn{2}{|c|}{0.740669} \\
\hline Log likelihood & \multicolumn{2}{|c|}{-766.124} & \multicolumn{2}{|c|}{-861.934358} \\
\hline Likelihood Ratio Test & \multicolumn{2}{|c|}{$4.201592^{* *}$} & \multicolumn{2}{|c|}{$7.335865 * * *$} \\
\hline AIC & \multicolumn{2}{|c|}{1550.25} & \multicolumn{2}{|c|}{1741.87} \\
\hline
\end{tabular}

Note: The significance levels of $1 \%, 5 \%$, and $10 \%$ are denoted by $* * *, * *$, and $*$, respectively. Standard errors are in parentheses.

(a) $W_{-} M C O S T$ indicates the spatial lag term of MCOST, where $\mathrm{W}$ is a weighted matrix whose element is 1 and 0 for contiguous and other regions, respectively.

(b) LAMBDA indicates spatially correlated errors and appears as an additional indicator in the spatial error method.

In Model 2 of Table 4, $W \_M C O S T$ is employed as an independent variable representing the spatial lag term of MCOST. Furthermore, its coefficient indicates the average influence of the MCOST of the neighboring gas distributors on the MCOST of the observed gas distributor, a positive effect with statistical significance. On the other hand, in Model 3, the spatially correlated error (LAMBDA) is employed as an independent variable. Overall, the fitness of the model improved in both cases, as reflected in their increased R-square and log likelihood. This result indicates that as compared to the 
OLS method, the spatial lag and spatial error methods are more appropriate for explaining MCOST and SSGEX.

\subsection{Geographically Specified Models}

As shown in Table 5, the newly included variables are $L O G P R D, L O G P R$, and SNOW DAYS. In Models 4 and 6, $L O G P R D$ is significant at the 5\% level. In Model 5, $L O G P R$ is also significant at the $5 \%$ level. All of these coefficients bear a negative sign, suggesting that higher industrial demand is associated with lower gas prices and costs, which also implies that industrial demand appears to capture economy of scale in the spatial model. SNOW DAYS indicates a contradictory result. In Model 4, SNOW DAYS is statistically insignificant at any level. However, this variable is significant at the $5 \%$ and 10\% level in Models 5 and 6, which indicates that while poor weather conditions escalate gas costs (manufacturing costs, in particular), they are statistically insignificant for gas prices.

Table 5. Regression result for the geographically specified models (OLS method)

\begin{tabular}{|c|c|c|c|c|c|}
\hline & Model 4 & \multicolumn{2}{|c|}{ Model 5} & \multicolumn{2}{|c|}{ Model 6} \\
\hline Regression Method & OLS & \multicolumn{2}{|c|}{ OLS } & \multicolumn{2}{|c|}{ OLS } \\
\hline Dependent Variable & PRICE & \multicolumn{2}{|c|}{ MCOST } & \multicolumn{2}{|c|}{ SSGEX } \\
\hline Constant & $212.2115^{* * *}$ (27.8948) & $78.9095 * * *$ & $(14.66965)$ & $86.5749 * * *$ & (30.83929) \\
\hline \multicolumn{6}{|l|}{ Demand density } \\
\hline LOG PRD & $-22.34961 * * *(4.853935)$ & & & $-11.41547 * *$ & $(5.366301)$ \\
\hline \multicolumn{6}{|l|}{ Demand size } \\
\hline$L O G P R$ & & $-3.6182 * *$ & (1.808733) & & \\
\hline \multicolumn{6}{|l|}{ Weather condition } \\
\hline SNOW DAYS & $0.03076604 \quad(0.06218375)$ & $0.1171299 * *$ & $(0.03575432)$ & $0.1188549 *$ & $(0.06874767)$ \\
\hline \multicolumn{6}{|l|}{ Management Efficiency } \\
\hline$D E P$ & $1.607808^{* * *}(0.1412702)$ & $0.4749813^{* * *}$ & $(0.08596579)$ & $1.867252^{* * *}$ & $(0.1561822)$ \\
\hline \multicolumn{6}{|c|}{ Characteristics and purchase methods of raw materials } \\
\hline LNGPIPE & $(5.77449)$ & -1.667961 & (3.43307) & 1.195494 & $(6.384028)$ \\
\hline LNGSATELLITE & $19.32722 * * * \quad(6.338928)$ & $6.510417^{*}$ & $(3.781744)$ & $14.20617^{* *}$ & $(7.008045)$ \\
\hline DNGPIPE & $-27.60948^{* * *}(6.137411)$ & $-20.58686 * * *$ & (3.697339) & $-13.24701^{*}$ & $(6.785257)$ \\
\hline DNGSATELLITE & $-1.919205 \quad(9.56384)$ & -2.329746 & $(5.747316)$ & -3.600508 & $(10.57337)$ \\
\hline LPGSATELLITE] & $37.18757 * * *(7.29902)$ & $20.22524 * * *$ & $(4.303829)$ & $34.74993 * * *$ & $(8.069482)$ \\
\hline R-Squared & 0.754254 & \multicolumn{2}{|c|}{0.646482} & \multicolumn{2}{|c|}{0.691265} \\
\hline Log likelihood & -858.351 & \multicolumn{2}{|c|}{-764.214} & \multicolumn{2}{|c|}{-876.816} \\
\hline F-statistic & 67.1398 & \multicolumn{2}{|c|}{40.003} & \multicolumn{2}{|c|}{48.9786} \\
\hline \multicolumn{6}{|l|}{ Diagnostics for spatial dependence } \\
\hline Moran's I (error) & 0.049927 & \multicolumn{2}{|c|}{0.045460} & \multicolumn{2}{|c|}{$0.063395^{*}$} \\
\hline Lagrange Multiplier (lag) & 0.0062299 & \multicolumn{2}{|c|}{0.4944734} & \multicolumn{2}{|c|}{0.0439355} \\
\hline Robust LM (lag) & 0.6814937 & \multicolumn{2}{|c|}{0.0180782} & \multicolumn{2}{|c|}{2.0831944} \\
\hline Lagrange Multiplier (error) & 0.9173015 & 0.760 & 5197 & 1.478 & 9610 \\
\hline Robust LM (error) & 1.5925653 & 0.284 & 1245 & 3.518 & $2199 *$ \\
\hline
\end{tabular}

Note: The significance levels are $1 \%, 5 \%$, and $10 \%$ are denoted by $* * *, * *$, and $*$, respectively. Standard errors are in parentheses.

More importantly, all three models (Models 4, 5, and 6) indicate the insignificance of Moran’s I 
at the $5 \%$ level. This result is remarkable when compared with Moran's I in Table 3, where all of the indices are significant. Moreover, all values of Moran's I are lower than those obtained using the conventional models. In other words, the geographically specified models capture the spatial dependence pattern better than conventional models.

Additionally, results for LM lag and error test are insignificant in Models 4, 5, and 6, which implies that the spatial lag and spatial error models are not useful in the geographically specified models. Therefore, spatial regressions are not conducted in this chapter.

\section{CONCLUSION}

A spatial approach has been highlighted in this paper toward analyzing the Japanese gas industry. First, the results of the ESDA indicated that positive spatial autocorrelations exist in gas prices, manufacturing costs, and expenditures throughout Japan. These results suggest that despite its monopolistic features, the Japanese gas industry is exposed to spatially dependent patterns. In locallevel analyses, the LISA identified a statistically strong spatial dependence among gas distributors in eastern Japan (low-low) essentially due to the domestic gas pipeline network.

Second, the results of the conventional regression models indicated that spatial dependences are statistically significant at the 5\% level for explaining gas prices and their costs, and these results imply that conventional independent variables such as economies of scale, management efficiency, and characteristics of raw materials and their purchase methods may not operate effectively as spatial determinants of gas prices, costs, and expenditures. The geographically specified model is superior in that the newly included independent variables, which capture geographical conditions including weather conditions, production shipment, and purchase method and availability of domestic natural gas, influence the spatially dependent pattern.

The deregulation policy on the Japanese gas industry that is being used now fails to consider 
these geographical conditions. In fact, current yardstick regulation attempts to consider regional differences by classifying gas distributors into the following four regional categories: the HokkaidoTohoku region, Kanto region, Chubu-Hokuriku-Kinki region, and Chugoku-Sikoku-Kyushu-Okinawa region. Whether or not these categories are based on any empirical rationale derived from formal research is indeed questionable. As indicated in this paper, regional features such as domestic gas source, production shipment, and production shipment density significantly influence the spatial dependence of gas prices and costs. Therefore, the current yardstick regulation might consider such regional features in order to promote fair competition in the Japanese gas industry.

This research can be enhanced by investigating a number of other factors. For example, given substitutability, the price of other energy utilities—electricity, kerosene, propane gas, and so on—may influence the price of gas and its spatial dependence. However, because of the limited availability of data, such an effect could not be analyzed here. Additionally, the researchers employed only the crosssectional data from 2007. Considering the time-variant nature of gas and other energy prices, it would be meaningful to use panel data for spatial analyses. 


\section{REFERENCES}

Agency for Natural Resources and Energy. (2007, October). Distributed material 3-1 at the 7th sectional meeting of Toshi netsu energy [Urban Heat Energy]. Retrieved from http://www.enecho.meti.go.jp/info/committee/commit17.htm\#01

Agency for Natural Resources and Energy. (2008). Gas business handbook (2007 ed.). Tokyo: The Japan Gas Association.

Agency for Natural Resources and Energy. (2009). Gas Annual Report (FY 2007). Tokyo: The Japan Gas Association.

Anselin, L. (1995). Local indicators of spatial association - LISA, Geographical Analysis, 27, 93-115.

Anselin, L. (2005). Exploring spatial data with $G e o D a^{T M}$ : A workbook, revised version, Center for Spatially Integrated Social Science.

Anselin, L., Sridharan, S., \& Gholston, S. (2007).Using exploratory spatial data analysis to leverage social indicator databases: The discovery of interesting patterns, Soc Indic Res, 82, 287-309.

Bivand, R., \& Szymanski, S. (1997). Spatial dependence through local yardstick competition: Theory and testing, Economics Letters, 55, 257-265.

Cabinet office, government of Japan Source. (2009, April). Koukyou ryoukin no mado [The window of public utility charges]. Retrieved from http://www5.cao.go.jp/seikatsu/koukyou/

Can, A., \& Megbolugbe, I. (1997). Spatial dependence and house price index construction, Journal of Real Estate Finance Econ, 14, 203-222.

Chi, G., \& Zhu, J. (2007). Spatial Regression Models for Demographic Analysis, Population Research and Policy Review, 27(1), 17-42.

Consumer Affair Agency, Government of Japan. (2010, January 20). Koukyou ryoukin no mado [The window of public utility charges]. Retrieved from

http://www.caa.go.jp/seikatsu/koukyou/index.html

Ito, Y. (2009). Toshi gasu sangyo no sougou bunseki [Evolution of the City Gas Industry]. In K. Takenaka (Ed.), Toshi gasu jigyou no nainai kakakusa mondai [Gas Price Differencial in City Gas Industry], (pp.111-126). Tokyo: NTT Publishing Co., Ltd.

Kainou, K. (2008). Toshi gasu jigyou ni okeru nai nai kakaku sa no teiryouteki hyouka bunseki [An empirical analysis of gas price differential], RIETI-Discussion Paper 08-J-001

Kitamura, M. (2001). Waga kuni denki jigyou niokeru kibo no keizaisei to kouritusei oyobi yousojyuyou bunseki [An analysis of economies of scale, efficiency and demand factors in Japanese electric power industry], Journal of Socio Economic Research, 45, 1-16.

Lee J. D., Park S. B., \& Kim T. Y. (1999). Profit productivity and price differential: An international performance comparison of the natural gas transportation industry, Energy Policy, 27, 679-689. 
Ministry of Economy, Trade and Industry. (2006). The distributed material 3-1 and 3-5 in the meetings of Sangyou kouzou singikai sin seichou seisaku bukai kyousou kankyou seibi syou iinkai [Competition Environment Planning Committee (Energy Working Group)]. Retrieved from http://www.meti.go.jp/committee/materials/g60627aj.html and http://www.meti.go.jp/committee/materials/g60815bj.html

Ministry of Economy, Trade and Industry. (2007). Indices of industrial production in 2007. Retrieved from http://www.meti.go.jp/statistics/tyo/kougyo/index.html

Ministry of Finance (n.d.). Trade Statistics of Japan. Retrieved from http://www.customs.go.jp/toukei/info/index.htm

Ministry of Internal Affairs and Communications, (2009). Social observations of Shi, Ku, Machi, Mura (2009 ed.). Tokyo: Statistics Bureau, Director-General for Policy Planning (Statistical Standards) and Statistical Research and Training Institute.

Ministry of Internal Affairs and Communications, (2009). Social observations of prefectures (2009 ed.). Tokyo: Statistics Bureau, Director-General for Policy Planning (Statistical Standards) and Statistical Research and Training Institute.

Nemoto, J. (1992). Denki jigyou no kibo no keizaisei: Saikin no kenkyuu no tenbou. [Economies of scale in electric power industry], Journal of Socio Economic Research, 31, 15-24.

Shinjo, K. (1997). Price and cost structure of the electric power industry: Some international comparisons. The Journal of Economics of Kwansei Gakuin University, 51(2), 1-33.

Takenaka, K., \& Urano, H. (1994). Toshi gasu [The city gas]. In M. Uekusa., \& T. Yokokura (Eds.), Hiyou bunseki: kibo no keizaisei wo chuusin ni [Cost analysis of gas price: Economies of scale analysis], (pp. 99-135). Tokyo: NTT Publishing Co., Ltd.

Yokokura, T. (1994). Toshi gasu [The city gas]. In M. Uekusa, \& T. Yokokura (Eds.), Kisei seisaku: sono wakugumi to tenkai [Regulatory policy: Its framework and development], (pp. 136-181). Tokyo: NTT Publishing Co., Ltd. 


\section{APPENDICES}

\section{A. Dependent and Independent Variables}

\section{- Dependent Variables}

This paper employs gas price as well as costs in order to understand the impact of geographical conditions on both. The three dependent variables are defined in the following manner:

PRICE (unit: yen/46 MJ)

$=\frac{\text { Annual gas aales volume (Unit: Yen) }}{\text { Annual gas supply amount (Unit: MI) }} \times 46$

MCOST (unit: yen/46 MJ)

$=\frac{\text { Annual manufacturing cost (Unit: Yen) }}{\text { Annual gas supply amount (Unit! MI) }} \times 46$

SSGEX (unit: yen/46 MJ)

= Anmual supply cost \& sales cast \& general expense (Unft: Yon)

Anrual gas supply amount (Unlt: MD) $\times 46(3)$

Table 6: Descriptive Statistics of the Three Dependent Variables ( $n=184$ unit: yen/46MJ)

\begin{tabular}{cccc}
\hline & PRICE & MCOST & SSGEX \\
\hline Mean & 141.2 & 68.0 & 83.8 \\
Standard Deviation & 52.0 & 26.0 & 51.3 \\
Minimum & 48.1 & 29.7 & 7.2 \\
Maximum & 260.1 & 220.6 & 240.4 \\
\hline \hline
\end{tabular}

Source: Gas Annual Report (2007)

\section{PRICE}

Fundamentally, it may be necessary to analyze gas prices (or the other two costs) by differentiating between the regulated and deregulated sector prices. However, accurate deregulated gas prices of each gas distributor are rarely disclosed to the public. Therefore, this paper employs the total average value of regulated and deregulated gas prices (or costs).

\section{MCOST}

MCOST is a dependent variable that includes all the costs involved in the manufacturing process including raw material cost, depreciation expense for manufacturing equipments such as re-gasification, operational cost such as payroll cost, and maintenance cost for manufacturing processes. Raw material cost accounts for a major proportion of the manufacturing costs. Table 7 indicates a comparison between the average import LNG price ${ }^{16}$ and total average manufacturing price per $46 \mathrm{MJ}$ in 2007 for the top four gas distributors: Tokyo Gas Co., Ltd.; Osaka Gas Co., Ltd.; Toho Gas Co., Ltd.; and Saibu Gas Co., Ltd.

\section{SSGEX}

SSGEX is a dependent variable calculated by subtracting the manufacturing cost from the total cost of producing one unit of gas. Supply cost includes all the costs for supplying gas to customers including

\footnotetext{
${ }^{16}$ The import price is based on the CIF (cost, insurance, and freight) price.
} 
depreciation expense for gas distribution facilities (pipelines, gas holders, pressure regulators, etc.) and operational cost for gas distribution processes. Sales costs include miscellaneous costs such as gas meter reading, and legal safety inspection of a customer's gas equipment. On the other hand, general administration expenses include costs for customer management such as gas rate contract and for general management, which include human resources and financial management as well as general affairs.

\section{- Independent variables}

The independent variables in the regression analysis are categorized into two groups. The first group includes the independent variables for the conventional model, which is associated with the second research question, and the second group includes the independent variables for the spatial model, which is associated with the third research question.

\section{The independent variables for the conventional model}

Based on previous studies, the independent variables for the conventional model represent three key determinants: economies of scale, management efficiency, and characteristics and purchase methods of the raw materials.

\section{LOG SUPPLY (unit: megajoule)}

The variable $L O G$ SUPPLY, which represents the annual gas supply volume, has been extensively used in existing studies for indicating economies of scale in the gas business. First, the two plausible explanations for the existence of a relationship between MCOST/46MJ and LOG SUPPLY are (i) the increased supply volume generates a volume discount while purchasing raw material, (ii) the increased supply volume decreases the average operational cost of the manufacturing facilities. Second, similar explanations that may be assumed for the relationship between SSGEX/46MJ and LOG SUPPLY are that (i) the increased supply volume increases the number of pipeline constructions, thereby generating a volume discount in the contract with the pipeline contractor, (ii) the increased supply volume decreases the average operational cost of manufacturing facilities. Therefore, LOG SUPPLY is assumed to have negative relationships with all three dependent variables: PRICE/46MJ, MCOST/46MJ, and SSGEX/46MJ.

\section{$D E P$ (unit: yen/46 megajoule)}

$D E P$, an independent variable, represents the total average depreciation expense for producing one unit of gas and management efficiency of the gas distributor. Essentially, the gas business is a capitalintensive industry; therefore, it is evident that the depreciation expenses of the manufacturing and supplying equipment significantly influences gas prices. $D E P$ is assumed to have positive relationships with the three dependent variables. Although a significant number of existing studies used the book value of fixed assets, annual depreciation expenses are more accurate for explaining gas prices because they are based on overall annual costs. Therefore, this paper uses the total average depreciation expense for producing one unit of gas, which is defined by the following equation.

$D E P=\frac{\text { Total annual deprislation expense (Unitilapanses yen) }}{\text { Annual ges supply amount (Unit : Mage [oule) }} \times 46$ (4)

\section{DIFFUSION R (unit: \%)}

The independent variable, DIFFUSION, is often used to represent gas management efficiency. This variable calculates the volume of gas diffused within a service area. This independent variable is 
defined in the following manner:

DIFFUSION $R^{17}=\frac{\text { Total number of gas meter in service area }}{\text { Number of household in service area }}$ (5)

\section{LNGPIPE, LNGSATELLITE, DNGPIPE, DNGSATELLITE, and LPGSATELLITE}

The characteristics of raw materials and their purchase methods are represented by LNGPIPE, LNGSATELLITE, DNGPIPE, DNGSATELLITE, and LPGSATELLITE. They have been extensively supported as determinants of gas price by numerous previous studies. Currently, three main categories of raw materials are available for the Japanese gas distributors: Liquefied Natural Gas (from abroad), Liquefied Petroleum Gas (from abroad), and Domestic Natural Gas. Moreover, there are three categories of purchase methods: LNG terminal, pipeline, and satellite. First, LNG terminal implies that the gas distributors import LNG from abroad directly and gasify it in their own LNG terminal. Only eight large gas distributors have employed this method because of the significant investment that is entailed. Second, the pipeline purchase method ${ }^{18}$ implies purchasing gasified LNG or domestic natural gas through pipelines from other energy companies (other gas distributors or electric power companies). Finally, the satellite method implies using a lorry, ship, or JR train for purchasing LNG, LPG, or domestic natural gas. Usually, relatively small gas distributors adopt this method. Table 7 represents six combinations of raw materials and purchase methods as well as their mean values for the three dependent variables.

Table 7: Combination of Raw Materials and their Purchase Methods

\begin{tabular}{ccccc}
\hline & Observations & Gas Price & MCOST/46MJ & SSGEX/46MJ \\
\hline LNGTERMINAL & 8 & 104.2 & 68.0 & 41.9 \\
LNGPIPE & 51 & 114.8 & 56.4 & 57.4 \\
LNGSATELLITE & 38 & 157.3 & 72.2 & 94.3 \\
DNGPIPE & 47 & 100.1 & 45.1 & 54.0 \\
DNGSATELLITE & 9 & 129.3 & 62.8 & 72.7 \\
LPGSATELLITE & 49 & 191.5 & 94.5 & 129.0 \\
\hline All & 184 & 141.2 & 68.0 & 83.8 \\
\hline
\end{tabular}

Note: Fifteen town gas distributors adopt several combinations of raw materials and purchase methods. Therefore, the actual total observations exceed 184.

As indicated in Table 7, the mean value of each raw material is different. In particular, from the six observations, LPGSATELLITE and DNGPIPE exhibit the highest and lowest mean gas prices.

Additionally, this paper uses the following five dummy variables.

LNGPIPE: (= 1 if purchase LNG through pipeline, and 0 otherwise)

LNGSATELLITE: (= 1 if purchase LNG through satellite system, and 0 otherwise)

DNGPIPE: (= 1 if purchase domestic natural gas through pipeline, and 0 otherwise)

DNGSATELLITE: (= 1 if purchase domestic natural gas through satellite, and 0 otherwise)

LPGSATELLITE: (= 1 if purchase LPG through satellite, and 0 otherwise)

\footnotetext{
${ }^{17}$ This diffusion rate may exceed $100 \%$ because a few customers own several gas meters. Due to the insignificance of this variable in the conventional method, it is not used in the geographically specified method.

${ }^{18}$ This method does not require that the gasification facilities or gas holder be owned by the distributors.
} 
If all of these five dummy variables are equal to 0 , it would imply that the observed gas distributor adopts the LNG terminal purchase method. Therefore, this paper defines five dummy variables in order to express all the characteristics and purchase methods of the raw materials.

\section{Independent variables for the geographically specified model}

Independent variables for the geographically specified model represent geographical conditions that are assumed to influence gas prices. This paper employs the following two variables as additional independent variables on the basis of a paper by the ANRE (2007).

\section{SNOW DAYS}

Cold weather is likely to positively influence gas prices. If demand for gas is extremely high during a particular period of time in the winter, the gas distributor is compelled to prepare manufacturing and supply facilities in order to meet this increased demand. In such a case, the working rate of the facilities during summer is relatively low, which may increase the average cost of one unit of gas. Moreover, heavy snowfall escalates cost, for such weather conditions require additional work in terms of clearing the snow.

\section{LOG PRD, LOG PR}

According to the ANRE (2007), the regional demand density such as population density may be an important determinant of gas price. This variable is considered to be strongly associated with $L O G$ $S U P P L Y$ in the conventional model. In fact, the correlation coefficient between $L O G S U P P L Y$ and $L O G P R D$ is 0.55 , which implies that they are correlated and discourages their simultaneous use in the regression model. Therefore, in this paper, regional demand density of each gas distributor is employed rather than LOG SUPPLY. It is necessary to examine whether population (household) or industrial production density is more significant for the gas business. LOG PRD has the most significant negative effect on the three dependent variables. Thus, in order to express the demand density of a regional gas service area more accurately, the annual production shipment per kilometer square of inhabitable land area $L O G P R D$ for every service area of a gas distributor is used in this paper, represented by the following equation:

$$
\text { LOG PRD }=\frac{\text { Annual Production Shlpment }(y e n)}{\text { The inhabitable area }\left(\mathrm{km}^{2}\right)}(6)
$$




\section{B. Domestic Gas Pipeline Network (INPEX CORPORATION)}

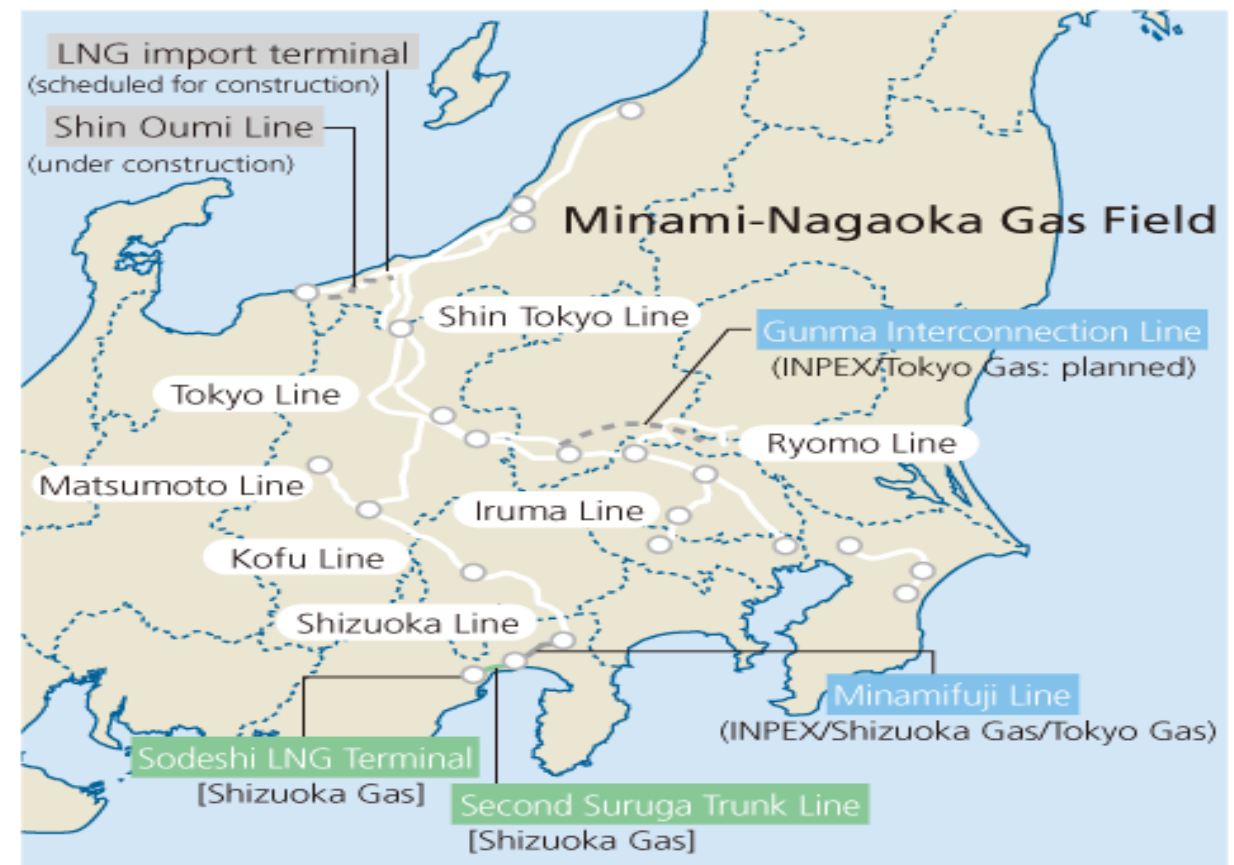

Domestic pipeline network

\section{Test of Spatial Dependence Framework, Anselin (2005)}

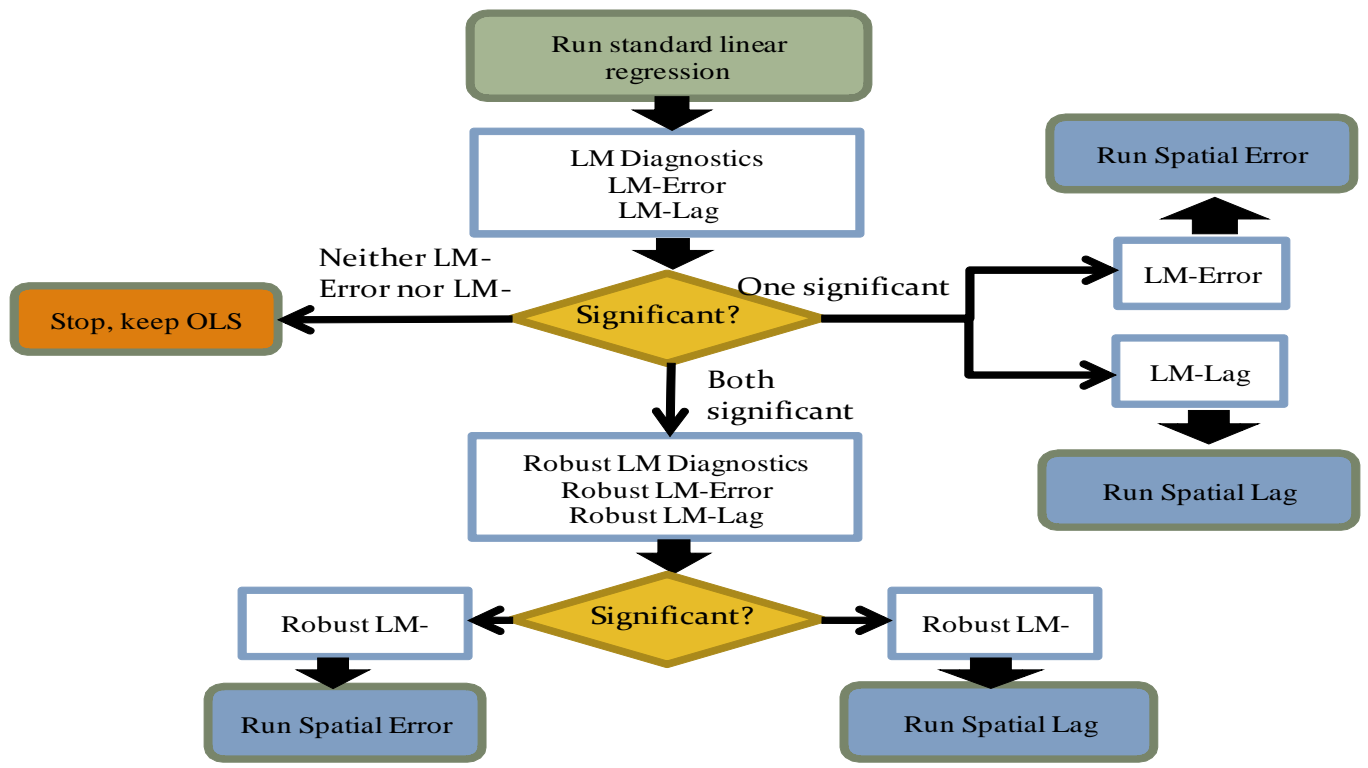

